\title{
Sleep quality and metabolic syndrome in overweight or obese children and adolescents
}

\author{
Qualidade do sono e síndrome metabólica \\ em crianças e adolescentes com \\ sobrepeso ou obesidade
}

Nathalia Costa GONZAGA'

Aline Silva Santos SENA ${ }^{2}$

Alexsandro Silva COURA ${ }^{3}$

Fábio Galvão DANTAS ${ }^{4}$

Renata Cardoso OLIVEIRA ${ }^{3}$

Carla Campos Muniz MEDEIROS ${ }^{3,}$

\section{Objective}

To assess sleep quality and its association with metabolic syndrome and its components.

\section{Methods}

This cross-sectional study was conducted from June 2011 to March 2012 at the Childhood Obesity Center, Campina Grande, Paraiba, Brazil, with 135 overweight or obese children and adolescents. Sleep quality was assessed by the Pittsburgh Sleep Quality Index. Metabolic syndrome diagnosis was based on abdominal circumference, blood pressure, glycemia, high density lipoprotein-cholesterol, and triglycerides. The data were treated by the software Statistical Package for the Social Sciences version 22.0 at a significance level of 5\%.

\footnotetext{
1 Universidade Federal do Ceará, Programa de Pós-Graduação em Enfermagem, Departamento de Enfermagem. Fortaleza, CE, Brasil.

2 Instituto Materno Infantil de Pernambuco, Programa de Pós-Graduação em Saúde Materno-Infantil. Recife, PE, Brasil.

3 Universidade Estadual da Paraíba, Centro de Ciências Biológicas e da Saúde, Programa de Pós-Graduação em Saúde Pública. Campina Grande, PB, Brasil.

4 Universidade Estadual da Paraíba, Centro de Ciências Biológicas e da Saúde, Departamento de Fisioterapia. Campina Grande, PB, Brasil.

5 Universidade Estadual da Paraíba, Programa de Pós-Graduação em Enfermagem. Av. das Baraúnas, 351, Bairro Universitário, 58429-500, Campina Grande, PB, Brasil. Correspondência para/Correspondence to: CCM MUNIZ. E-mail: <carlamunizmedeiros@hotmail.com>.

Support: Pró-Reitoria de Pós-Graduação e Pesquisa of Universidade Estadual da Paraíba (Process nº 093/2011) and Fundação de Apoio à Pesquisa do Estado da Paraíba (Process nº 198/08).
} 


\section{Results}

The prevalence of poor sleep quality or sleep disorder according to the Pittsburgh Sleep Quality Index was $40.7 \%$, and females had higher mean global Pittsburgh Sleep Quality Index score. Metabolic syndrome prevalence was $63.0 \%$. Females also had higher daytime dysfunction. Poor sleep quality was associated with high diastolic blood pressure $(\mathrm{OR}=2.6 ; p=0.015)$ and waist circumference $(\mathrm{OR}=3.17 ; p=0.024)$ after adjusting for sex and age.

\section{Conclusion}

Girls had higher global Pittsburgh Sleep Quality Index score, which was associated with daytime dysfunction. Poor sleep quality was a predictor of high diastolic blood pressure in the study sample.

Keywords: Adolescent. Child. Metabolic syndrome. Obesity. Sleep.

\section{R E S U M O}

\section{Objetivo}

Avaliar a qualidade do sono e sua associação com a síndrome metabólica e seus componentes.

\section{Métodos}

Estudo transversal, realizado entre junho de 2011 e março de 2012 no Centro de Obesidade Infantil, Campina Grande, Paraiba. Foram incluídas 135 crianças e adolescentes com sobrepeso ou obesidade. A qualidade do sono foi avaliada pelo Pittsburgh Sleep Quality Index. Para o diagnóstico de síndrome metabólica, consideraram-se circunferência abdominal, pressão arterial, glicemia, lipoproteínas de alta densidade e triglicerídeos. Os dados foram analisados pelo Statistical Package for the Social Sciences versão 22.0, sendo adotado um nível de significância de 5\%.

\section{Resultados}

A prevalência de má qualidade ou distúrbio do sono avaliado pelo Pittsburgh Sleep Quality Index foi 40.7\%, e a média do escore global Pittsburgh Sleep Quality Index foi significativamente maior no sexo feminino. A prevalência de síndrome metabólica foi 63.0\%. A disfunção diurna foi significativamente maior no sexo feminino. A má qualidade do sono esteve associada à pressão arterial diastólica elevada $(O R=2,6 ; p=0,015)$ e à circunferência abdominal elevada $(O R=3,17 ; p=0,024)$, após ajuste para sexo e idade.

\section{Conclusão}

As meninas apresentaram um maior escore global do Pittsburgh Sleep Quality Index e associação com a disfunção diurna. A má qualidade do sono mostrou-se fator preditor de pressão arterial diastólica elevada na amostra estudada.

Palavras-chave: Adolescente. Criança. Síndrome metabólica. Obesidade. Sono.

\section{INTRODUCTION}

Sleep is a vital necessity and its periodicity, quality, and constancy characterize very important variables in the development of children and adolescents ${ }^{1}$. Changes in sleep pattern and quality can affect people at a very young age and their consequences range from poor school performance to compromised physical and mental health².

In the last years, the prevalence of voluntary sleep restriction, insomnia, and even poor sleep quality has increased concomitantly with the growing prevalence of obesity in children and adolescents ${ }^{3}$.

The reason for the relationship between sleep and obesity has not been fully elucidated. Studies suggest that partial or chronic sleep deprivation causes energy unbalance by changing the levels of many hormones, including leptin and grehlin 4,5 , whose function relates to energy balance and control of body weight ${ }^{6,7}$ and insulin.

Regarding insulin, short sleep duration may be associated with insulin resistance ${ }^{6}$, which 
is related to the metabolic syndrome in overweight and obese children and adolescents ${ }^{8}$.

Hence, sleep has an important metabolic role as it may promote endocrine and metabolic changes that increase hunger and appetite, and consequently, the risk of overweight and obesity8.

Adolescents with short sleep duration $(<7$ hours/night) had lower intake of fruits and vegetables and higher intake of fast foods ${ }^{9}$. Along with inappropriate eating habits, it is possible that qualitative and quantitative sleep changes reduce the level of physical activity in children and adolescents ${ }^{1}$.

Most studies on the association between sleep and obesity in children assess sleep duration ${ }^{9-15}$, and few assess sleep quality 14,16,17. However, assessment of sleep duration alone is not enough, qualitative aspects must also be assessed ${ }^{18}$. This is because when individuals have difficulty falling asleep or when they wake up frequently, effective sleep duration decreases, and the body does not spend enough time in deep sleep stages, even if total sleep duration is adequate $^{19}$.

Questionnaires have been used for diagnosing sleep disorders, and although they are indirect and subjective assessment instruments, their administration requires little time, and they are free and easy to use in epidemiological studies ${ }^{16,17,20}$.

The Pittsburg Sleep Quality Index (PSQI) is an instrument commonly used for assessing sleep quality $^{17,21}$. The version validated for the Brazilian population was developed in a study that compared PSQI and polysomnography, the gold standard sleep quality assessment method in adults. The results have shown that the Brazilian PSQI version is a valid and reliable instrument for assessing sleep quality in the month prior to the interview ${ }^{22}$.

Some studies have reported that sleep quality in adults assessed by the PSQI is associated not only with excess weight, but also with metabolic syndrome ${ }^{18,21}$. Metabolic syndrome is an aggregation of cardiometabolic risk factors represented by hypertension, abdominal obesity, hypertriglyceridemia, low High Density Lipoproteincholesterol (HDL-c), and glucose intolerance ${ }^{23}$. Therefore, the detection of this condition at an early age is important for the implementation of prevention strategies.

In adolescents short sleep duration was associated with overweight but not with metabolic syndrome. Short sleep duration was associated with high blood pressure, and long sleep duration, with hypertriglyceridemia ${ }^{12}$.

Nevertheless, until now, no study has assessed the association between sleep quality and metabolic syndrome in children and adolescents. Moreover, studies that assess sleep quality in this population are scarce.

Hence, in order to contribute to this qualitative sleep aspect, and given the repercussion of sleep disorders on overweight and obese individuals, this study aimed to assess sleep quality and its association with the metabolic syndrome and its components in overweight or obese children and adolescents.

\section{METHODS}

This cross-sectional study was conducted during the school year from June 2011 to March 2012 at the Childhood Obesity Center, located in the Instituto de Saúde Elpídeo de Almeida, Campina Grande (PB), Brazil. Childhood Obesity Center is a reference public service for providing multidisciplinary care to overweight and obese children and adolescents. Currently, 390 children and adolescents are registered.

This study is part of a larger project called "Prevalence of cardiometabolic risk factors in overweight or obese children and adolescents", approved by the Research Ethics Committee of the Universidade Estadual da Paraíba (UEPB) under Protocol $n^{\circ}$ 0040.0.133.000-08. The study followed all the ethical precepts for human research. 
The convenience sample consisted of all overweight and obese children and adolescents aged 5 to 18 years who attended the routine medical visit on Fridays during the school year, since sleep habits change during vacations ${ }^{24}$. Students with adenotonsillar hypertrophy; cardiorespiratory, neuromuscular, neoplastic, and/or advanced hepatic disease; and taking drugs that affected sleep (antidepressants, benzodiazepines, bronchodilators, corticosteroids, and illicit drug or alcohol abuse) at data collection were excluded.

During this period 190 individuals were treated. Seventeen of these were excluded, eleven because they were outside the study age range, two were normal weight, two had asthma, and two had adenoid hypertrophy. Thirty-three individuals did not show up for blood collection and five did not have one of the results for metabolic syndrome components, so the final sample consisted of 135 individuals.

The anthropometric variables (weight, height, and abdominal circumference) were measured twice and averaged, as recommended by the World Health Organization ${ }^{25}$.

Nutritional status classification was based on Body Mass Index (BMI), as recommended by the Centers of Disease Control and Prevention: overweight ( $85^{\text {th }}$ percentile $\leq \mathrm{BMI}<95^{\text {th }}$ percentile), obesity ( $95^{\text {th }}$ percentile $\leq \mathrm{BMI}<97^{\text {th }}$ percentile), and morbid obesity $\left(97^{\text {th }} \text { percentile } \leq \mathrm{BMI}\right)^{26}$. Abdominal circumference was considered high when $\geq 90^{\text {th }}$ percentile, as recommended by the International Diabetes Federation ${ }^{27}$, with a maximum limit of $88 \mathrm{~cm}$ for girls and $102 \mathrm{~cm}$ for boys, as recommended by the National Cholesterol Education Program Adult Treatment Panel III (NCEP/ATPIII) ${ }^{28}$.

Blood pressure was measured three times two minutes apart each, as recommended by the $\checkmark$ Brazilian Guidelines for High Blood Pressure ${ }^{29}$ using a mercury Tycos ${ }^{\circledR}$ sphygmomanometer made in Germany by WelchAllyn and appropriatesize cuff. The mean of the two last measurements was considered the systolic and diastolic blood pressure.
Blood was collected after a 12-hour fast by the Laboratory of Clinical Analyses of the UEPB. $\mathrm{HDL}-\mathrm{C}$, triglycerides, and glycemia were assessed by enzyme colorimetry by an automatic device (Modelo BioSystems 310, Curitiba, Paraná, Brazil).

Metabolic syndrome diagnosis was based on the criteria provided by NCEP/ATPIII ${ }^{28}$ adapted for the age group, which requires the presence of at least three of these criteria: abdominal circumference $\geq 90^{\text {th }}$ percentile for sex, age, and race; triglycerides $\geq 100 \mathrm{mg} / \mathrm{dL} ; \mathrm{HDL}-\mathrm{c}<45 \mathrm{mg} / \mathrm{dL}$; fasting glycemia $\geq 100 \mathrm{mg} / \mathrm{dL}$; and systolic and/or diastolic blood pressure $\geq 90^{\text {th }}$ percentile for sex, height, and age.

The Pittsburg Sleep Quality Index ${ }^{30}$ assessed sleep quality during the previous month. This Portuguese version of this instrument has been validated $^{31}$. PSQI contains seven components: subjective sleep quality (subjective sensation of satisfaction with daily sleep), sleep latency (long sleep start time), sleep duration, habitual sleep efficiency (proportion between hours slept and total hours in bed), sleep disorders (sleep interruption), use of sleeping pills, and daytime dysfunction.

The global score is given by adding the seven components. Each component receives a score ranging from 0 to 3 points with the same weight, and 3 represents the negative extreme of a Likert-type scale. Hence, the total score may range from 0 to 21 points. Sleep quality is classified as follows: $0-5=$ good sleep quality; $6-10=$ poor sleep quality; $>10=$ sleep disorder. All participants with a PSQI score higher than 5 (PSQI >5) were diagnosed with poor sleep quality as the score indicates great difficulty in at least two components, or moderate difficulty in more than three components ${ }^{30}$.

The score of each component was also assessed and compared with metabolic syndrome and its components. Subjective sleep quality scored 0-3 points ( 0 - very good sleep quality; 1 - good sleep quality; 2 - bad sleep quality; and 3 - very bad sleep quality). Sleep latency scored 0-3 points (time in minutes required to fall asleep 
every night and frequency of not falling asleep within 30 minutes). Sleep duration scored 0-3 points $(0=$ sleep duration $>7$ hours; $1=6-\leq 7$ hours; $2=5-<6$ hours; $3=<5$ hours). Habitual sleep efficiency scored 0-3 points (classified according to the sum of the answers related to sleeping problems caused by nine reasons and their frequency, such as feeling hot or cold: $0=0 ; 1=9-1$; $2=10-18 ; 3=19-27)$. The use of sleeping pills scored $0-3$ points $(0=$ did not use in the last month; 1 = used less than once a week; $2=$ used once or twice a week; $3=$ used three or more times a week). Daytime dysfunction scored 0-3 points (classified according to the sum of the answers related to the frequency of having problems to stay awake while driving, during meals, or during social activities, and the frequency of having problems to remain enthusiastic enough to carry out activities of daily living: $0-0 ; 1-2=1$; $3-4=2 ; 5-6=3$ ).

The population was described according to their anthropometric and clinical variables, expressed as absolute and relative frequencies, means, and standard deviations. Group means were compared by the Student's $t$ test or Analysis of Variance (Anova) for three groups and the proportions were compared by the Chi-square test or Fisher's exact test. Univariate logistic regression assessed the relationship between metabolic syndrome and its components and sleep disorder diagnosed based on PSQI score, which was later adjusted for sex and age. The Odds Ratio (OR) was calculated based on logistic regression. The logistic regression was performed by transforming the PSQI variable into dummy variables, the reference group being good sleep quality.

The statistical analyses were performed by the software Statistical Package for the Social Sciences (SPSS Inc., Chicago, Illinois, United States), version 22.0, at a significance level of $5 \%$.

\section{RE S U L T S}

Table 1 shows the sample characteristics. Of the 135 study children and adolescents, 56.3\% were females, $64.4 \%$ were classified as morbidly obese, and $76.3 \%$ were adolescents. The mean age was $12.7 \pm 3.4$ years (5.0-20.0). Sex was associated with nutritional status, males were associated with morbid obesity when the groups morbid obesity and obesity were compared $(p=0.010)$.

The prevalence of poor sleep quality/sleep disorder according to the PSQI score was $40.7 \%$, and the prevalence was higher in females (44.7 versus $35.6 \%$ ) (Table 1).

More than half (55.6\%) the sample classified their sleep in the previous month as bad or very bad. Metabolic syndrome prevalence was $63.0 \%$. Low HDL-c and blood glucose changes were the most and least frequent metabolic syndrome components, respectively. High abdominal circumference was associated with being male (Table 1).

The mean Pittsburgh Sleep Quality Index score of adolescents was higher than that of children. While adolescents had a mean score of $5.21 \pm 2.60$ (4.70-5.72), children had a mean score of $4.44 \pm 3.29(3.25-5.62)(p=0.170)$.

Pittsburgh Sleep Quality Index component with the highest mean was subjective sleep quality. Females had higher mean scores in six PSQI components, except efficiency, and the mean daytime dysfunction score was significantly higher in girls (Table 2).

The mean Pittsburgh Sleep Quality Index and PSQI component scores were not different between those with and without metabolic syndrome, regardless of sex. Although no association was found in females with metabolic syndrome, most of their PSQI items had higher mean scores than those of males with metabolic syndrome (Table 3).

Pittsburgh Sleep Quality Index and/or its components were not associated with metabolic syndrome, according to logistic regression (Table 4).

Logistic regression analysis between PSQI and metabolic syndrome components showed 
Table 1. Characterization of the entire sample and by sex ( $N=135)$. Campina Grande (PB), Brazil, 2011-2012.

\begin{tabular}{|c|c|c|c|c|c|c|c|}
\hline \multirow{3}{*}{ Variables } & \multirow{2}{*}{\multicolumn{2}{|c|}{ Total population }} & \multicolumn{4}{|c|}{ Sex } & \multirow{3}{*}{$p$} \\
\hline & & & \multicolumn{2}{|c|}{ Male } & \multicolumn{2}{|c|}{ Female } & \\
\hline & $\mathrm{M}$ & $\mathrm{DP}$ & $\mathrm{M}$ & DP & M & DP & \\
\hline Age (years) & 12.70 & 3.40 & 12.16 & 3.26 & 13.11 & 3.41 & 0.102 \\
\hline Body mass index & 29.84 & 5.90 & 30.26 & 6.97 & 29.51 & 4.94 & 0.471 \\
\hline \multirow[t]{2}{*}{ Mean sleep duration (h/day) } & 8.45 & 1.84 & 8.76 & 1.64 & 8.21 & 1.95 & 0.086 \\
\hline & $n$ & $\%$ & $n$ & $\%$ & $n$ & $\%$ & \\
\hline \multicolumn{8}{|l|}{ Age group } \\
\hline Child (6 to 9 years) & 32 & 23.7 & 17 & 28.8 & 15 & 19.7 & 0.219 \\
\hline Adolescent (10 to 18 years) & 103 & 76.3 & 42 & 71.2 & 61 & 80.3 & \\
\hline \multicolumn{8}{|l|}{ Body mass index percentile } \\
\hline Overweight & 5 & 3.7 & 2 & 3.4 & 3 & 3.9 & 0.036 \\
\hline Obese & 43 & 31.9 & 12 & 20.3 & 31 & 40.8 & \\
\hline Morbidly obese & 87 & 64.4 & 45 & 76.3 & 42 & 55.3 & \\
\hline \multicolumn{8}{|l|}{ Sleep quality } \\
\hline Good quality (PSQI $\leq 5)$ & 80 & 59.3 & 38 & 64.4 & 42 & 55.3 & 0.113 \\
\hline Poor quality (PSQI 6-10) & 46 & 34.1 & 20 & 33.9 & 26 & 34.2 & \\
\hline Sleep disorder (PSQI >10) & 9 & 6.7 & 1 & 1.7 & 8 & 10.5 & \\
\hline \multicolumn{8}{|l|}{ PSQI scores } \\
\hline $0-1$ & 11 & 8.1 & 6 & 10.2 & 5 & 6.6 & 0.162 \\
\hline $2-3$ & 32 & 23.7 & 15 & 25.4 & 17 & 22.4 & \\
\hline $4-5$ & 37 & 27.4 & 17 & 28.8 & 20 & 26.3 & \\
\hline $6-7$ & 29 & 21.5 & 16 & 27.1 & 13 & 17.1 & \\
\hline $8-9$ & 17 & 12.6 & 4 & 6.8 & 13 & 17.1 & \\
\hline $10-11$ & 6 & 4.4 & 1 & 1.7 & 5 & 6.5 & \\
\hline $12-13$ & 3 & 2.2 & 0 & 0.0 & 3 & 3.9 & \\
\hline $14-15$ & 0 & 0.0 & 0 & 0.0 & 0 & 0.0 & \\
\hline $16-21$ & 0 & 0.0 & 0 & 0.0 & 0 & 0.0 & \\
\hline \multicolumn{8}{|l|}{ Subjective sleep quality } \\
\hline Very good & 33 & 24.4 & 16 & 27.1 & 17 & 22.4 & 0.531 \\
\hline Good & 27 & 20.0 & 11 & 18.6 & 16 & 21.1 & \\
\hline Bad & 45 & 33.4 & 22 & 37.3 & 23 & 30.3 & \\
\hline Very bad & 30 & 22.2 & 10 & 16.9 & 20 & 26.3 & \\
\hline \multicolumn{8}{|l|}{ Sleep latency } \\
\hline 0 & 67 & 49.6 & 30 & 50.8 & 37 & 48.7 & 0.464 \\
\hline 1 & 36 & 26.7 & 17 & 28.8 & 19 & 25.0 & \\
\hline 2 & 19 & 14.1 & 9 & 15.3 & 10 & 13.2 & \\
\hline 3 & 13 & 9.6 & 3 & 5.1 & 10 & 13.2 & \\
\hline \multicolumn{8}{|l|}{ Sleep duration } \\
\hline$>7$ hours & 114 & 84.4 & 52 & 88.1 & 62 & 81.6 & 0.427 \\
\hline $6-7$ hours & 11 & 8.1 & 5 & 8.5 & 6 & 7.9 & \\
\hline 5- 6 hours & 7 & 5.2 & 1 & 1.7 & 6 & 7.9 & \\
\hline$<5$ hours & 3 & 2.2 & 1 & 1.7 & 2 & 2.6 & \\
\hline \multicolumn{8}{|l|}{ Habitual sleep efficiency } \\
\hline $0(\geq 85 \%)$ & 133 & 98.5 & 58 & 98.3 & 75 & 98.7 & 1.000 \\
\hline $1(75-84 \%)$ & 2 & 1.5 & 1 & 1.7 & 1 & 1.3 & \\
\hline $2(65-74 \%)$ & 0 & 0.0 & 0 & 0.0 & 0 & 0.0 & \\
\hline $3(<65 \%)$ & 0 & 0.0 & 0 & 0.0 & 0 & 0.0 & \\
\hline \multicolumn{8}{|l|}{ Sleep disorders } \\
\hline 0 & 16 & 11.9 & 7 & 11.9 & 9 & 11.8 & 0.164 \\
\hline 1 & 86 & 63.7 & 42 & 71.2 & 44 & 57.9 & \\
\hline 2 & 30 & 22.2 & 8 & 13.6 & 22 & 28.9 & \\
\hline 3 & 3 & 2.2 & 2 & 3.4 & 1 & 1.3 & \\
\hline
\end{tabular}


Table 1. Characterization of the entire sample and by sex (N=135). Campina Grande (PB), Brazil, 2011-2012.

\begin{tabular}{|c|c|c|c|c|c|c|c|}
\hline \multirow{3}{*}{ Variables } & \multirow{2}{*}{\multicolumn{2}{|c|}{ Total population }} & \multicolumn{4}{|c|}{ Sex } & \multirow{3}{*}{$p$} \\
\hline & & & \multicolumn{2}{|c|}{ Male } & \multicolumn{2}{|c|}{ Female } & \\
\hline & $M$ & DP & M & DP & $\mathrm{M}$ & DP & \\
\hline \multicolumn{8}{|c|}{ Use of sleeping pills } \\
\hline 0 & 36 & 26.7 & 18 & 30.5 & 18 & 23.7 & 0.778 \\
\hline 1 & 77 & 57.0 & 33 & 55.9 & 44 & 57.9 & \\
\hline 2 & 19 & 18.1 & 7 & 11.9 & 12 & 15.8 & \\
\hline 3 & 3 & 2.2 & 1 & 1.7 & 2 & 2.6 & \\
\hline \multicolumn{8}{|c|}{ Daytime dysfunction } \\
\hline 0 & 110 & 81.5 & 54 & 91.5 & 56 & 73.7 & 0.068 \\
\hline 1 & 9 & 6.7 & 2 & 3.4 & 7 & 9.2 & \\
\hline 2 & 12 & 8.8 & 2 & 3.4 & 10 & 13.2 & \\
\hline 3 & 4 & 3.0 & 1 & 1.7 & 3 & 3.9 & \\
\hline \multicolumn{8}{|c|}{ Metabolic syndrome } \\
\hline Present & 85 & 63.0 & 41 & 69.5 & 44 & 57.9 & 0.166 \\
\hline Absent & 50 & 17.0 & 18 & 31.5 & 32 & 42.1 & \\
\hline \multicolumn{8}{|c|}{ N metabolic syndrome components } \\
\hline 0 & 1 & 0.7 & 0 & 0.0 & 1 & 1.3 & 0.313 \\
\hline 1 & 11 & 8.1 & 2 & 3.4 & 9 & 11.8 & \\
\hline 2 & 38 & 28.1 & 16 & 27.1 & 22 & 28.9 & \\
\hline 3 & 56 & 41.5 & 28 & 47.5 & 28 & 36.8 & \\
\hline 4 & 28 & 20.7 & 12 & 20.3 & 16 & 21.1 & \\
\hline 5 & 1 & 0.7 & 1 & 1.7 & 0 & 0.0 & \\
\hline \multicolumn{8}{|c|}{ Abdominal circumference } \\
\hline High & 102 & 75.6 & 51 & 86.4 & 51 & 67.1 & 0.010 \\
\hline Normal & 33 & 24.4 & 8 & 13.6 & 25 & 32.9 & \\
\hline \multicolumn{8}{|c|}{ Blood Pressure } \\
\hline High & 72 & 53.3 & 32 & 54.2 & 40 & 52.6 & 0.853 \\
\hline Normal & 63 & 46.7 & 27 & 45.8 & 36 & 47.4 & \\
\hline \multicolumn{8}{|c|}{ Systolic blood pressure } \\
\hline High & 27 & 20.0 & 10 & 16.9 & 17 & 22.4 & 0.435 \\
\hline Normal & 108 & 80.0 & 49 & 83.1 & 59 & 77.6 & \\
\hline \multicolumn{8}{|c|}{ Diastolic blood pressure } \\
\hline High & 62 & 45.9 & 28 & 47.5 & 34 & 44.7 & 0.753 \\
\hline Normal & 73 & 54.1 & 31 & 52.5 & 42 & 55.3 & \\
\hline \multicolumn{8}{|c|}{ Fasting glycemia } \\
\hline High & 1 & 0.7 & 1 & 1.7 & 0 & 0.0 & 0.437 \\
\hline Normal & 134 & 99.3 & 58 & 98.3 & 76 & 100.0 & \\
\hline \multicolumn{8}{|c|}{ Triglycerides } \\
\hline High & 85 & 63.0 & 40 & 67.8 & 45 & 59.2 & 0.306 \\
\hline Normal & 50 & 17.0 & 19 & 32.2 & 31 & 40.8 & \\
\hline \multicolumn{8}{|c|}{ High density lipoprotein-cholesterol } \\
\hline Low & 112 & 83.0 & 47 & 79.7 & 65 & 85.5 & 0.369 \\
\hline Normal & 23 & 17.0 & 12 & 20.3 & 11 & 14.5 & \\
\hline
\end{tabular}

Note: Difference between the groups with morbid obesity and obesity, $p=0,010$; Difference between the groups with overweight and obesity, $p=0.573$; Difference between the groups with morbid obesity and overweight, $p=0.610$.

SD: Standard Deviation; PSQI: Pittsburgh Sleep Quality Index. 
Table 2. Mean values and standard deviations of the Pittsburgh Sleep Quality Index (PSQI) domains by sex (N=135). Campina Grande (PB), Brazil, 2011-2012.

\begin{tabular}{|c|c|c|c|c|c|c|c|}
\hline \multirow{2}{*}{ Variables } & \multicolumn{2}{|c|}{ Study population } & \multicolumn{2}{|c|}{ Males } & \multicolumn{2}{|c|}{ Females } & \multirow{2}{*}{$p$} \\
\hline & $M$ & SD & $M$ & SD & M & SD & \\
\hline PSQI score & 5.03 & 2.78 & 4.44 & 2.31 & 5.49 & 3.04 & 0.025 \\
\hline Subjective sleep quality & 1.53 & 1.09 & 1.44 & 1.07 & 1.61 & 1.11 & 0.387 \\
\hline Sleep latency & 0.84 & 1.00 & 0.75 & 0.90 & 0.91 & 1.07 & 0.353 \\
\hline Sleep duration & 0.25 & 0.65 & 0.17 & 0.53 & 0.32 & 0.73 & 0.181 \\
\hline Sleep efficiency & 0.01 & 0.12 & 0.02 & 0.13 & 0.01 & 0.11 & 0.858 \\
\hline Sleep disorders & 1.15 & 0.64 & 1.08 & 0.62 & 1.20 & 0.65 & 0.313 \\
\hline Use of sleeping pills & 0.92 & 0.70 & 0.85 & 0.69 & 0.97 & 0.71 & 0.302 \\
\hline Daytime dysfunction & 0.33 & 0.76 & 0.15 & 0.55 & 0.47 & 0.87 & 0.010 \\
\hline
\end{tabular}

Note: M: Média; SD: Standard Deviation.

Table 3. Comparison between global Pittsburgh Sleep Quality Index (PSQI) score and its components by presence of metabolic syndrome (N=135). Campina Grande (PB), Brazil, 2011-2012.

\begin{tabular}{|c|c|c|c|c|c|c|c|}
\hline \multirow{2}{*}{ Variables } & \multicolumn{3}{|c|}{ Presence of metabolic syndrome } & \multicolumn{3}{|c|}{ Absence of metabolic syndrome } & \multirow{2}{*}{$p$} \\
\hline & Mean & SD & $95 \% \mathrm{Cl}$ & Mean & SD & $95 \% \mathrm{Cl}$ & \\
\hline \multicolumn{8}{|l|}{ Males } \\
\hline Global PSQI score & 4.41 & 2.29 & 3.69-5.14 & 4.50 & 2.43 & $3.29-5.71$ & 0.898 \\
\hline Subjective sleep quality & 1.44 & 1.09 & $1.09-1.79$ & 1.44 & 1.04 & $0.93-1.96$ & 0.986 \\
\hline Sleep latency & 0.73 & 0.89 & $0.45-1.01$ & 0.78 & 0.94 & $0.31-1.25$ & 0.858 \\
\hline Sleep duration & 0.24 & 0.62 & $0.05-0.44$ & 0.00 & 0.00 & $0.00-0.00$ & 0.104 \\
\hline Habitual sleep efficiency & 0.00 & 0.00 & $0.00-0.00$ & 0.06 & 0.23 & $-0.06-0.17$ & 0.132 \\
\hline Sleep disorders & 1.10 & 0.70 & $0.88-1.32$ & 1.06 & 0.42 & $0.85-1.26$ & 0.814 \\
\hline Use of sleeping pills & 0.76 & 0.62 & $0.56-0.95$ & 1.06 & 0.80 & $0.66-1.45$ & 0.126 \\
\hline Daytime dysfunction & 0.15 & 0.57 & $-0.03-0.33$ & 0.17 & 0.51 & $-0.09-0.42$ & 0.898 \\
\hline \multicolumn{8}{|l|}{ Females } \\
\hline Global PSQI score & 5.57 & 3.07 & $4.64-6.50$ & 5.38 & 3.06 & $4.27-6.48$ & 0.787 \\
\hline Subjective sleep quality & 1.61 & 1.10 & $1.28-1.95$ & 1.59 & 1.13 & $1.19-2.00$ & 0.939 \\
\hline Sleep latency & 0.93 & 1.09 & $0.60-1.26$ & 0.88 & 1.07 & $0.49-1.26$ & 0.821 \\
\hline Sleep duration & 0.34 & 0.80 & $0.10-0.59$ & 0.28 & 0.63 & $0.05-0.51$ & 0.729 \\
\hline Habitual sleep efficiency & 0.02 & 0.15 & $-0.02-0.07$ & 0.00 & 0.00 & $0.00-0.00$ & 0.397 \\
\hline Sleep disorders & 1.18 & 0.62 & $0.99-1.37$ & 1.22 & 0.71 & $0.96-1.47$ & 0.810 \\
\hline Use of sleeping pills & 0.95 & 0.72 & $0.74-1.17$ & 1.00 & 0.72 & $0.74-1.26$ & 0.787 \\
\hline Daytime dysfunction & 0.48 & 0.88 & $0.21-0.74$ & 0.47 & 0.88 & $0.15-0.79$ & 0.967 \\
\hline
\end{tabular}

Note: SD: Standard Deviation; 95\%Cl: 95\% Confidence Interval.

that individuals with poor sleep quality were up to 2.5 times more likely to have high diastolic blood pressure $(p=0.018 ; 95 \%$ Confidence Inteval-95\% Cl=1.17-5.43), and the risk increased to $2.62(p=0.01 ; 95 \% \mathrm{Cl}=1.20-5.69)$ after adjusting for sex and age (OR=2.62) (Table 5).

After adjusting the components for sex and age, high abdominal circumference was associated with poor sleep quality $(\mathrm{OR}=3.17$; $p=0.02 ; 95 \% \mathrm{Cl}=1.17-8.60$ ) (Table 5).
The possibility of sleep disorder was not associated with metabolic syndrome components probably because of the small sample size.

\section{DISCUSSION}

It is critical to identify sleep disorders during childhood because of the importance of introducing strategies to promote sleep quality and prevent metabolic complications, such as 
Table 4. Odds Ratio (OR) of metabolic syndrome by Pittsburgh Sleep Quality Index (PSQI) and its components (N=135). Campina Grande (PB), Brazil, 2011-2012.

\begin{tabular}{|c|c|c|c|c|c|}
\hline Variables & Score & $n$ & $\mathrm{OR}$ & $(95 \% \mathrm{Cl})$ & $p$ \\
\hline \multirow[t]{2}{*}{ Global PSQI score } & $\leq 5$ & 80 & 1.00 & Reference & \\
\hline & $>5$ & 55 & 0.73 & $(0.35-1.49)$ & 0.391 \\
\hline \multirow[t]{4}{*}{ Subjective sleep quality } & 0 & 33 & 1.00 & Reference & \\
\hline & 1 & 27 & 1.42 & $(0.50-4.00)$ & 0.511 \\
\hline & 2 & 45 & 1.14 & $(0.46-2.82)$ & 0.766 \\
\hline & 3 & 30 & 1.94 & $(0.68-5.49)$ & 0.210 \\
\hline \multirow[t]{4}{*}{ Sleep latency } & 0 & 67 & 1.00 & Reference & \\
\hline & 1 & 36 & 1.18 & $(5.23-2.69)$ & 0.684 \\
\hline & 2 & 19 & 0.53 & $(0.17-1.64)$ & 0.270 \\
\hline & 3 & 13 & 0.93 & $(0.27-3.13)$ & 0.902 \\
\hline \multirow[t]{4}{*}{ Sleep duration } & 0 & 114 & 1.00 & Reference & \\
\hline & 1 & 11 & 0.94 & $(0.26-3.41)$ & 0.929 \\
\hline & 2 & 7 & 1.24 & $(0.26-5.80)$ & 0.786 \\
\hline & 3 & 3 & 2.67 & $(0.00-0.00)$ & 0.999 \\
\hline \multirow[t]{4}{*}{ Habitual sleep efficiency } & 0 & 133 & 1.00 & Reference & \\
\hline & 1 & 2 & 0.58 & $(0.036-9.536)$ & 0.705 \\
\hline & 2 & 0 & - & - & - \\
\hline & 3 & 0 & - & - & - \\
\hline \multirow[t]{4}{*}{ Sleep disorders } & 0 & 16 & 1.00 & Reference & \\
\hline & 1 & 86 & 0.56 & $(0.19-1.65)$ & 0.296 \\
\hline & 2 & 30 & 0.76 & $(0.23-2.58)$ & 0.666 \\
\hline & 3 & 3 & 0.50 & $(0.04-6.68)$ & 0.600 \\
\hline \multirow[t]{4}{*}{ Use of sleeping pills } & 0 & 36 & 1.00 & Reference & \\
\hline & 1 & 77 & 0.79 & $(0.36-1.78)$ & 0.581 \\
\hline & 2 & 19 & 0.57 & $(0.18-1.86)$ & 0.357 \\
\hline & 3 & 3 & 0.62 & $(0.05-7.53)$ & 0.711 \\
\hline \multirow[t]{4}{*}{ Daytime dysfunction } & 0 & 110 & 1.00 & Reference & \\
\hline & 1 & 9 & 1.14 & $(0.27-4.82)$ & 0.856 \\
\hline & 2 & 12 & 0.57 & $(0.17-1.89)$ & 0.359 \\
\hline & 3 & 4 & 1.71 & $(0.17-17.03)$ & 0.645 \\
\hline
\end{tabular}

Note: $95 \% \mathrm{Cl}: 95 \%$ Confidence Interval.

excess weight ${ }^{10,32}$. Sleep disorders are often underdiagnosed in this age group as they depend on the perception of caregivers given that children do not always verbalize symptoms related to this condition ${ }^{33}$.

Sleep quality in this study was measured by the PSQI index and its components (subjective quality, latency, duration, habitual efficiency, sleep disorders, use of sleeping pills, and daytime sleepiness) in a group of children and adolescents with excess weight, and the prevalence of poor sleep quality in the sample was high.

A study with Brazilian university students with a mean age of 21.5 years found that $95.3 \%$ had poor sleep quality (PSQI >5), and the mean PSQI score was 9.4 points $^{34}$.

Some factors that may influence sleep quality in children and adolescents are long periods watching television ${ }^{35}$ and changes in the daily routine and habit during vacations. This last item leads to changes in sleeping pattern, such as going to bed later and consequently, getting less rapid eye movement sleep. Both factors were associated with a higher risk for obesity in children and adolescents $^{36}$.

Poor sleep quality was more prevalent among the study adolescents. This condition may affect wake quality to a variable degree, especially in this age group, since they go to bed late in 
Table 5. Logistic regression between Pittsburgh Sleep Quality Index and components of metabolic syndrome adjusted for age and sex (N=135). Campina Grande (PB), Brazil, 2011-2012.

\begin{tabular}{|c|c|c|c|c|c|c|}
\hline \multirow{2}{*}{ Pittsburgh Sleep Quality Index } & \multicolumn{3}{|c|}{ Univariate analysis } & \multicolumn{3}{|c|}{ Adjusted for sex and age } \\
\hline & OR & $(95 \% \mathrm{Cl})$ & $p$ & OR & $(95 \% \mathrm{Cl})$ & $p$ \\
\hline \multicolumn{7}{|l|}{ Metabolic syndrome } \\
\hline $0-5$ & & 1.00 & Reference & & 1.00 & Reference \\
\hline $6-10$ & 1.52 & $(0.70-3.29)$ & 0.284 & 1.60 & $(0.73-3.51)$ & 0.242 \\
\hline$>10$ & 0.83 & $(0.21-3.34)$ & 0.797 & 0.98 & $(0.24-4.08)$ & 0.983 \\
\hline \multicolumn{7}{|l|}{ Diastolic blood pressure } \\
\hline $0-5$ & & 1.00 & Reference & & 1.00 & Reference \\
\hline $6-10$ & 2.53 & $(1.17-5.43)$ & 0.018 & 2.62 & $(1.20-5.69)$ & $0.015^{*}$ \\
\hline$>10$ & 0.55 & $(0.13-2.36)$ & 0.424 & 0.50 & $(0.11-2.21)$ & 0.363 \\
\hline \multicolumn{7}{|l|}{ Systolic blood pressure } \\
\hline $0-5$ & & 1.00 & Reference & & 1.00 & Reference \\
\hline $6-10$ & 0.70 & $(0.28-1.75)$ & 0.444 & 0.73 & $(0.29-1.86)$ & 0.515 \\
\hline$>10$ & 0.24 & $(0.06-1.03)$ & 0.054 & 0.25 & $(0.06-1.10)$ & 0.067 \\
\hline \multicolumn{7}{|l|}{ Triglycerides } \\
\hline $0-5$ & & 1.00 & Reference & & 1.00 & Reference \\
\hline $6-10$ & 0.68 & $(0.32-1.45)$ & 0.322 & 0.68 & $(0.32-1.46)$ & 0.325 \\
\hline$>10$ & 0.38 & $(0.09-1.55)$ & 0.180 & 0.43 & $(0.10-1.78)$ & 0.246 \\
\hline \multicolumn{7}{|c|}{ High density lipoprotein cholesterol } \\
\hline $0-5$ & & 1.00 & Reference & & 1.00 & Reference \\
\hline $6-10$ & 1.89 & $(0.64-5.60)$ & 0.249 & 1.81 & $(0.61-5.43)$ & 0.287 \\
\hline$>10$ & 0.46 & $(0.10-2.06)$ & 0.311 & 0.38 & $(0.08-1.82)$ & 0.226 \\
\hline \multicolumn{7}{|l|}{ Abdominal circumference } \\
\hline $0-5$ & & 1.00 & Reference & & 1.00 & Reference \\
\hline $6-10$ & 2.25 & $(0.88-5.75)$ & 0.091 & 3.17 & $(1.17-8.60)$ & $0.024^{*}$ \\
\hline$>10$ & 0.81 & $(0.19-3.50)$ & 0.775 & 1.12 & $(0.22-5.69)$ & 0.891 \\
\hline
\end{tabular}

Note: ${ }^{*} p<0.05$.

OR: Odds Ratio; 95\% Cl: 95\% Confidence Interval.

their biological configuration and tend to wake up late, which is not possible during the school year, resulting in excessive daytime sleepiness ${ }^{37}$.

A study of Brazilian adolescents using the Sleep Behavior Questionnaire found that the obese group had worse sleep quality than the normal weight group ${ }^{16}$.

Females had higher mean global PSQI and daytime dysfunction scores than males. This association with being female corroborates a study done with 1,481 adults that also assessed the relationship between sleep quality and metabolic syndrome by sex ${ }^{18}$.

Although sleep quality was not associated with metabolic syndrome in the present study, sleep quality was associated with diastolic blood pressure and abdominal circumference.
Another two studies did not find an association between sleep duration and metabolic syndrome ${ }^{12,38}$. In male and female adults, the mean global PSQI score and the mean score of its components, especially sleep latency and sleep disorders, have been associated with metabolic syndrome ${ }^{18}$.

Adolescents with sleep-related breathing disorders diagnosed by polysomnography were seven times more likely to have metabolic syndrome than those without sleep-related breathing disorders $(\mathrm{OR}=7.74 ; 95 \% \mathrm{Cl}=3.10-19.35)$, and this association was not explained by sex, race, or socioeconomic condition ${ }^{39}$.

High diastolic blood pressure was found in children with obstructive sleep apnea ${ }^{40}$. Adolescents with low sleep efficiency determined 
by actigraphy were 3.5 times more likely to have high blood pressure ${ }^{41}$, a higher risk than the one found by the present study. This fact may be due to the different methods used for determining sleep quality.

A study that assessed sleep quality with full-night polysomnography found that the absence of deeper sleep stages, such as rapid eye movement sleep and slow-wave sleep, was associated with high morning blood pressure in obese adolescents regardless of $\mathrm{BMI}^{42}$.

A study with obese Korean adolescents found that short sleep duration was associated not only with high blood pressure but also with high abdominal circumference ${ }^{12}$.

In the present study, high abdominal circumference was associated with poor sleep quality after adjusting for age and sex, and may be used as a marker of sleep quality ${ }^{12}$.

In this sense, assessment of obese adolescents must include investigation of blood pressure, abdominal circumference, and the signs and symptoms associated with poor sleep quality, including snoring, fatigue, and daytime sleepiness. Thus, poor sleep quality must be considered in the follow-up of hypertensive obese youth ${ }^{42}$.

The present study found a high prevalence of poor sleep quality and the need of including this assessment in primary health care, especially in obese individuals. Health professionals who work with children and adolescents must know sleep physiology and its physiological maturation process to prevent or treat pathological behaviors. Therefore, questions regarding sleep quality and possible damaging factors should be included in the patient's assessment, in addition to advice on sleep hygiene, which should be part of children's health care ${ }^{32}$.

Sleep hygiene practices include changes in the sleep environment, and parents' and children's practices and routines that favor good sleep quality of adequate duration, in addition to the practice of activities that favor sleepiness in order to promote sleep ${ }^{43}$.
This study has limitations, such as the use of a convenience sample, the absence of a control group, the cross-sectional design, which does not allow the identification of the relationship of causality, and the use of a questionnaire to assess sleep quality, which although equivalent, is less accurate than other analytical methods such as polysomnography and actigraphy. The relative scarcity of pediatric studies that analyze the relationship between sleep quality and metabolic syndrome hindered comparison of the results.

The study is important because the assessment of the sleep quality of overweight and obese children and adolescents revealed a high prevalence of poor sleep quality and its association with high diastolic blood pressure in adolescents.

\section{CONCLUSION}

Girls had higher global Pittsburgh Sleep Quality Index score and an association between said score and daytime dysfunction. Sleep quality was not associated with metabolic syndrome in the study overweight or obese children and adolescents. Adolescents with poor sleep quality were significantly more likely to have high diastolic blood pressure.

The realization of other studies on this subject in other Brazilian municipalities with a larger sample, control group, and longitudinal design may contribute to the understanding of the influence of sleep quality on metabolic changes, risk factors for cardiovascular disease and indispensable for the institution of child health policies in the national landscape.

\section{CONTRIBUTORS}

NC GONZAGA and ASS SENA participated in the project design, analysis and interpretation of data and writing of the manuscript. AC COURA and FG DANTAS contributed to the writing and critical review of the manuscript. RC OLIVEIRA participated in the project design and final revision of the manuscript. CCM MEDEIROS participated in the project design, data analysis and final revision of the manuscript. 


\section{REFERENCES}

1. American Academy of Pediatrics. School start times for adolescents. Pediatrics. 2014; 134(3):642-9. http://dx.doi.org/10.1542/peds.2014-1697

2. Shochat T, Cohen-Zion M, Tzischinsky O. Functional consequences of inadequate sleep in adolescents: A systematic review. Sleep Med Rev. 2014; 18(1):75e87. http://dx.doi.org/10.1016/j.smrv. 2013.03.005

3. Logue EE, Scott ED, Palmieri PA, Dudley P. Sleep duration, quality, or stability and obesity in an urban family medicine center. J Clin Sleep Med. 2014; 10(2):177-82. http://dx.doi.org/10.5664/jcsm.3448

4. Cao M, Zhu Y, He B, Yang W, Chen Y, Jun M, et al. Association between sleep duration and obesity is age- and gender-dependent in Chinese urban children aged 6-18 years: A cross-sectional study. BMC Public Health. 2015; 15(1029):1-10. http:// dx.doi.org/10.1186/s12889-015-2359-0

5. Zhang B, Hao Y, Zhou J, Jia F, Li X, Tang Y, et al. The association between sleep patterns and overweight/ obesity in Chinese children: A cross-sectional study. Neuropsychiatr Dis Treat. 2015; 11:2209-16. http:// dx.doi.org/10.2147/NDT.S90838

6. Fatima Y, Doi SAR, Mamun AA. Longitudinal impact of sleep on overweight and obesity in children and adolescents: A systematic review and bias-adjusted meta-analysis. Obesity Rev. 2015; 16(2):137-49. http://dx.doi.org/10.1111/obr.12245

7. Gonzaga NC, Medeiros CCM, de Carvalho DF, Alves JGB. Leptin and cardiometabolic risk factors in obese children and adolescents. J Paediatr Child Health. 2014; 50:707-12. http://dx.doi.org/10.11 11/jpc. 12610

8. Medeiros CCM, Ramos AT, Cardoso MAA, França ISX, Cardoso AS, Gonzaga NC. Insulin resistance and its association with metabolic syndrome components. Arq Bras Cardiol. 2011; 97(5):380-9.

9. Kruger AK, Reither EN, Peppard PE, Krueger PM, Hale L. Do sleep-deprived adolescents make lesshealthy food choices? $\mathrm{Br} J$ Nutr. 2014; 111(10):1898-904. http://dx.doi.org/10.1017/S00 07114514000130

10. Magee C, Iverson PCD. Lack of sleep could increase obesity in children and too much television could be partly to blame. Acta Paediatrica. 2014; 103(1):e27-e31. http://dx.doi.org/10.1111/apa.12 447

11. Martinez SM, Tschann JM, Greenspan LC, Deardorff J, Penilla C, Flores E, et al. Is it time for bed? Short sleep duration increases risk of obesity in Mexican American children. Sleep Med. 2014; 15(12):1484-9.
12. Lee JA, Park HS. Relation between sleep duration, overweight, and metabolic syndrome in Korean adolescents. Nutr Metab Cardiovasc Dis. 2014; 24(1):65-71. http://dx.doi.org/10.1016/j.numecd. 2013.06.004

13. Scharf RJ, Deboer MD. Sleep timing and longitudinal weight gain in 4- and 5-year-old children. Pediatr Obes. 2014; 10(2):141-8. http://dx.doi.org/10. 1111/ijpo.229

14. Boeke CE, Storfer-Isser A, Redline S, Taveras EM. Childhood sleep duration and quality in relation to leptin concentration in two cohort studies. Sleep. 2014; 37(3):613-20. http://dx.doi.org/10.5665/sleep. 3510

15. Kjeldsen JS, Hjorth MF, Andersen R, Michaelsen KF, Tetens I, Astrup A, et al. Short sleep duration and large variability in sleep duration are independently associated with dietary risk factors for obesity in Danish school children. Int J Obes. 2014; 38(1):32-9. http://dx.doi.org/10.1038/ijo.2013.147

16. Turco G, Bobbio T, Reimão R, Rossini S, Pereira $H$, Barros Filho A. Quality of life and sleep in obese adolescents. Arq Neuropsiquiatr. 2013; 71(2):78-82. http://dx.doi.org/10.1590/\$0004-282X2013005 000008

17. Tan E, Healey D, Gray AR, Galland BC. Sleep hygiene intervention for youth aged 10 to 18 years with problematic sleep: A before-after pilot study. BMC Pediatrics. 2012; 12(189):1-9. http://dx.doi.org/10. 1186/1471-2431-12-189

18. Okubo N, Matsuzaka M, Takahashi I, Sawada K, Sato S, Akimoto N, et al. Relationship between selfreported sleep quality and metabolic syndrome in general population. BMC Public Health. 2014; 14(562):1-7. http://dx. doi.org/10.1186/1471-24 58-14-562

19. Michels N, Verbeiren A, Ahrens W, de Henauw S, Sioen I. Children's sleep quality: Relation with sleep duration and adiposity. Public Health. 2014; 128(5):488-90. http://dx.doi.org/10.1016/j.puhe. 2014.02.003

20. Hanne KJG, Adam TC, Hursel R, Rutters F, Verhoef SPM, Westerterp-Plantenga MS. Sleep duration, sleep quality and body weight: Parallel developments. Physiol Behav. 2013; 121:112-6. http://dx.doi.org/ 10.1016/j.physbeh.2013.04.007

21. Hung HC, Yang YC, Ou HY, Wu JS, Lu FH, Chang CJ. The Association between self-reported sleep quality and metabolic syndrome. Plos One. 2013; 8(1):e54304. http://dx.doi.org/10.1371/journal. pone.0054304

22. Bertolazi AN, Fagondes SC, Hoof L, Dartora EG, Miozzo ICS, Barba MEF, et al. Validation of the Brazilian Portuguese version of the Pittsburgh Sleep 
Quality Index. Sleep Med. 2011; 12(1):70-5. http://dx. doi.org/10.1016/j.sleep.2010.04.020

23. Neto AS, Bozza R, Ulbrich A, Mascarenhas LPG, Boguszewski MC, Campos W. Síndrome metabólica em adolescentes de diferentes estados nutricionais. Arq Bras Endocrinol Metab. 2012; 56(2):104-9. http://dx.doi.org/10.1590/S0004-2730201200 0200003

24. Hart CN, Cairns A, Jelalian E. Sleep and obesity in children and adolescents. Pediatr Clin North Am. 2011; 58(3):715-33.

25. World Health Organization. Physical status: The use and interpretation of anthropometry. Technical Report Series, nº 854. Geneva: WHO; 1995.

26. Centers of Disease Control and Prevention. Table for calculated body mass index values for selected highs and weights for ages 2 to 20 years. Atlanta, GA: National Center for Health Statistic; 2000 [cited 2014 April 6]. Available from: http://www.cdc.gov/ growthcharts

27. International Diabetes Federation. Worldwide definition of metabolic syndrome. Brussels: International Diabetes Federation; 2005 [cited 2014 Jun 10]. Available from: http://www.idf.org/home/ index.cfm?node $=1429$

28. The Third Report of the National Cholesterol Education Program. Expert Panel on Detection. Evaluation, and treatment of high blood cholesterol in adults (Adult Treatment Panel III). JAMA. 2002; 285(19):2486-97.

29. Sociedade Brasileira de Cardiologia. V Diretrizes Brasileiras de Hipertensão Arterial. Arq Bras Cardiol. 2007; 89(3):24-79.

30. Buysse DJ, Reynolds CF, Monk TH, Berman SR, Kupfer D. The Pittsburgh Sleep Quality Index: A new instrument for psychiatric practice and research. Psychiatry Res. 1989; 28(2):193-213.

31. Bertolazi AN, Fagondes SC, Hoof L, Dartora EG, Miozzo ICS, Barba MEF, et al. Validation of the Brazilian Portuguese version of the Pittsburgh Sleep Quality Index. Sleep Med. 2011; 12(1):70-5. http:// dx.doi.org/10.1016/j.sleep.2010.04.020

32. Halal CS, Nunes ML. Education in children's sleep hygiene: Which approaches are effective? A systematic review. J Pediatr. 2014; 90(5):449-56. http://dx.doi.org/10.1016/j.jped.2014.05.001

33. Verhulst SL, Schrauwen N, Haentjens D, Rooman RP, Van Gall L, De Backer WA, et al. Sleep-disordered breathing and the metabolic syndrome in overweight and obese children and adolescents. J Pediatr. 2007; 150(6):608-12.
34. Araújo MFM, Lima ACS, Alencar AMPG, de Araújo TM, Fragoaso LVC, et al. Avaliação da qualidade do sono de estudantes universitários de Fortaleza - CE. Texto Contexto Enferm. 2013; 22(2):352-60. http:// dx.doi.org/10.1590/S0104-07072013000200011

35. Sijtsma A, Koller M, Sauer PJJ, Corpeleijn E. Television, sleep, outdoor play and BMI in young children: The GECKO Drenthe cohort. Eur J Pediatr. 2015; 174(5):631-9. http://dx.doi.org/10.1007/s00 431-014-2443-y

36. Hart CN, Cairns A, Jelalian E. Sleep and obesity in children and adolescents. Pediatr Clin North Am. 2011; 58(3):715-33.

37. Sena ASS, Cardoso AS, De Carvalho DF, Medeiros JL, Coutinho GF, Albuquerque $\mathrm{FCL}$, et al. Excessive daytime sleepiness and cardiometabolic risk factors in children and teenagers with overweight. J Hum Growth Dev. 2013; 23(1):24-30.

38. Sung $V$, Beebe DW, Vandyke $R$, Fenchel MC, Crimmins NA, Kirk $S$, et al. Does sleep duration predict metabolic risk in obese adolescents attending tertiary services? A cross-sectional study. Sleep. 2011; 34(7):891-8. http://dx.doi.org/10.5665/ SLEEP. 1122

39. Redline $S$, Storfer-Isser $A$, Rosen $C L$, Johnson $N L$, Kirchner HL, Emancipator J, et al. Association between metabolic syndrome and sleep-disordered breathing in adolescents. Am J Respir Crit Care Med. 2007; 176(4):401-8.

40. Marcus CL, Greene MG, Carroll JL. Blood pressure in children with obstructive sleep apnea. Am J Respir Crit Care Med. 1998; 157(4 Pt. 1):1098-103.

41. Javaheri S, Isser AS, Rosen CL, Redline S. Sleep quality and elevated blood pressure in adolescents. Circulation. 2008; 118(10):1034-40. http://dx. doi.org/10.1161/CIRCULATIONAHA.108.766410

42. Hannon TS, Tu W, Watson SE, Jalou H, Chakravorty S, Arslanian SA. Morning blood pressure is associated with sleep quality in obese adolescents. J Pediatr. 2014; 164(2):313-7. http://dx.doi.org/10.1016/j. jpeds.2013.10.011

43. Gruber R, Cassoff J, Knäuper B. Sleep health education in pediatric community settings: Rationale and practical suggestions for incorporating healthy sleep education into pediatric practice. Pediatr Clin North Am. 2011; 58(3):735-54. http:// dx.doi.org/10.1016/j.pcl.2011.03.006

Received: June 24, 2015

Final version: November 4, 2015 Approved: January 4, 2016 
